\title{
Research Article \\ Effect of Rubberwood Content on Biodegradability of Poly(butylene succinate) Biocomposites
}

\author{
Hemhong Anankaphong, ${ }^{1}$ Duanghathai Pentrakoon, ${ }^{1}$ and Jirawut Junkasem ${ }^{2}$ \\ ${ }^{1}$ Department of Materials Science, Faculty of Science, Chulalongkorn University, Bangkok 10330, Thailand \\ ${ }^{2}$ PTT Research and Technology Institute, PTT Public Company Limited, Ayutthaya 13170, Thailand \\ Correspondence should be addressed to Hemhong Anankaphong; hemhong.a@gmail.com \\ and Duanghathai Pentrakoon; duanghat@yahoo.com
}

Received 15 June 2015; Revised 8 September 2015; Accepted 21 September 2015

Academic Editor: Yiqi Yang

Copyright (c) 2015 Hemhong Anankaphong et al. This is an open access article distributed under the Creative Commons Attribution License, which permits unrestricted use, distribution, and reproduction in any medium, provided the original work is properly cited.

Poly(butylene succinate) (PBS) biocomposites incorporated with rubberwood powder (RWP) were fabricated with various RWP weight fractions (i.e., 0 to $40 \% \mathrm{wt}$ ) by injection moulding process. The soil burial test was employed to examine the biodegradability of such biocomposites under outdoor environment for 60 days. The physical appearance, percentage weight loss, chemical structure, and mechanical properties before and after the soil burial test were determined. Apparent changes in physical appearance of the biocomposites from optical micrographs were detected in terms of surface morphology and colour. The percentage of crystallinity of PBS/RWP biocomposites was studied by the X-ray diffraction (XRD) technique, and the XRD pattern revealed a decrease in percentage of crystallinity due to enhancing RWP weight fractions. This may be attributed to a presence of rubberwood powders providing more disordered molecular chain arrangement of PBS matrix and also an agglomeration of the rubberwood powder content at greater concentration as seen in SEM micrographs. With increasing RWP weight fractions and burial time, the results exhibited a considerable change in chemical structure (essentially ester linkage due to biodegradation mechanism of PBS), relatively greater percentage weight loss, and a substantial decrease in flexural properties. Consequently, the results indicate that incorporating RWP enhances biodegradability of PBS/RWP biocomposites; that is, the biodegradation rate of biocomposites increases with increasing RWP weight fractions and burial time.

\section{Introduction}

With a considerable emphasis on environmental concerns about an enormous plastic consumption in recent years, the concerns about usage and disposal are diverse, for example, an accumulation of waste in landfills and in natural habitats, the leaching of chemicals from plastic products, and the potential for plastics to transfer chemicals to wildlife and humans [1-3]. Biocomposites (i.e., environmentally friendly composite materials) have received substantial attention from industries and academic circles as evidenced by numerous patents and research publications [4-16].

Typically, biocomposites are composite materials comprising one or more phase(s) derived from a biological origin, for example, a composition between nonbiodegradable/biodegradable polymers as matrix and biodegradable natural fibres $[8,17]$. As a consequence of environmental issues, the biodegradable polymers have received enormous attention because they provide complete degradation in soil or by composting process and hardly release any harmful elements $[7,10,18]$.

Amid current commercially available biodegradable polymers, poly(butylene succinate) (PBS) happens to be attractive on account of its excellent biodegradability in nature like in soil, lake sea, and compost, excellent processability, being processible by most of conventional plastics processing machines, good thermal stability and high toughness related to its low glass transition, good thermal and chemical resistance, and being entirely combustible by fire without any toxic gases $[8,10,15,19-21]$. PBS is an aliphatic polyester, which can be synthesized through the polycondensation reaction of 1,4-butanediol and succinic acid [9]. PBS can degrade under natural environment by bacteria and fungi $[1,12]$. This is attributed to PBS chemical 
structure containing hydrolysable linkage along polymer backbone chain where it is a biodegradable mechanism initiated by hydrolysis mechanism at ester linkage [22]. General mechanism of polymer biodegradation is breaking polymer chain into small molecules (e.g., oligomers, dimers, and monomers) by enzymes or the environmental factors such as temperature, humidity, $\mathrm{pH}$, and sunlight. Then, small molecules are transported inside the microorganism cell to be utilized as carbon and energy sources. The end products of mineralization are $\mathrm{CO}_{2}, \mathrm{H}_{2} \mathrm{O}, \mathrm{CH}_{4}$, and microbial biomass [23]. PBS has been used in many applications replacing conventional plastic such as mulch film, bags, cups, and packaging film [24].

Natural biobased filler incorporated biodegradable polymers have attracted a great deal of interest owing to the naturally degradable materials into the soil burial environment $[9,25]$. Besides, the natural biobased filler has several advantages over inorganic fillers, such as renewability, low cost, low density, lower $\mathrm{CO}_{2}$ emission, biodegradability, and ecofriendliness $[14,26]$. In recent years, there have been many researches with reference to PBS incorporated with lignocellulosic materials as natural filler, such as lignin, coconut, rice husk, bamboo, coir, and wood [14, 14, 27, 28]. Thailand appears to be one of the world's largest producers of rubberwood products, for example, furniture, toys, and particle boards. During the production, many sawdust wastes are generated and become burden to the manufacturer, for example, environmental pollution, and generating additional operation cost. Hence, some attempts have been made to use rubber sawdust as filler in polymer composites [2931], however; the biodegradability of a composition between rubber sawdust and nonbiodegradable polymer has barely been studied.

In this research, biodegradability of neat PBS and PBS/ RWP biocomposites via soil burial test was studied under outdoor environment for 60 days. The physical appearance, percentage weight loss, chemical structure, and mechanical properties before and after the soil burial test were determined. As reported regarding the percentage of crystallinity influencing the biodegradability and mechanical properties $[32,33]$, hence, the percentage of crystallinity of the neat PBS and PBS/RWP biocomposites was studied by the X-ray diffraction (XRD) technique.

\section{Experimental}

2.1. Materials. Poly(butylene succinate) (PBS, density of $1.26 \mathrm{~g} / \mathrm{cm}^{3} ;$ MFI $=40 \mathrm{~g} / 10 \mathrm{~min}$ at load of $21.18 \mathrm{~N}, 190^{\circ} \mathrm{C}$ ) was supplied by Mitsubishi Chemical (Thailand) Company Limited. Rubberwood powders (RWP) having a particle size of 80 Mesh were supplied by Suppaisarn Thai Wood Powder Company Limited (Bangkok, Thailand).

2.2. Biocomposite Preparation. The PBS pellets were dried at $80^{\circ} \mathrm{C}$ in a vacuum oven for 24 hours prior to mixing. A specified content of PBS/RWP compounds (i.e., 5\%, 10\%, $20 \%, 30 \%$, and $40 \% \mathrm{wt}$ ) was mixed with PBS in a LTE-2644 , Labtech twin screw extruder at a screw speed of $30 \mathrm{rpm}$ and temperature profile of extruder from $140^{\circ} \mathrm{C}$ to $175^{\circ} \mathrm{C}$. The extrudate strands were cooled in a water bath and then pelletized.

Prior to biocomposite fabrication, the PBS/RWP compound pellets were dried at $60^{\circ} \mathrm{C}$ in a vacuum oven for 24 hours. Subsequently, the samples were fabricated using an injection moulding machine (HM 65/210s, Battenfeld) at $150 \mathrm{rpm}$ injection speed, 150-bar injection pressure, temperature profile from $135^{\circ} \mathrm{C}$ to $145^{\circ} \mathrm{C}$, and 25 -second cooling time.

2.3. Characterization. To assess the percentage of crystallinity of the neat PBS and PBS/RWP compounds, X-ray diffraction (XRD) analysis (D8, Bruker AXS) with $\mathrm{Cu} \mathrm{Ka}$ radiation $(0.154 \mathrm{~nm})$ was conducted 1 time/sample. Composites were scanned under diffraction angle $2 \theta$ in the range of 5 to $40^{\circ}$ using fixed time mode with step interval of $0.02^{\circ}$.

The chemical structure of biocomposites was characterized by attenuated total reflection mode or FTIR-ATR (NICOLET 6700, Thermo scientific). The FTIR spectra were recorded in a range of $400-4000 \mathrm{~cm}^{-1}$ with a resolution of $4.0 \mathrm{~cm}^{-1}$ and scanning 64 scans. Carbonyl index was calculated by the following [34]:

$$
\text { Carbonyl Index }(\mathrm{CI})=\frac{I_{1712}}{I_{1420}},
$$

where $I_{1712}$ is the peak intensity at $1712 \mathrm{~cm}^{-1}$ representing $\mathrm{C}=\mathrm{O}$ stretching of ester linkage and $I_{1420}$ is the peak intensity at $1420 \mathrm{~cm}^{-1}$ representing a stretching of methyl group, which was chosen as the reference peak.

Besides, the morphology of impact fractured surface of the neat PBS and biocomposites was investigated using a Scanning Electron Microscope (JSM-6480LV, JEOL). The specimens were coated with a thin layer of gold before viewing on the SEM. The micrographs at 500x and $3000 \mathrm{x}$ magnification with an accelerating voltage of $15 \mathrm{kV}$ were obtained.

2.4. Soil Burial Test. The $2.5 \times 12.7 \times 3.3 \mathrm{~mm}$ sample dimension was used for biodegradability test. The samples were buried beneath the farmland soil containing $0.35 \%$ nitrogen, $0.10 \%$ phosphorous, $1.37 \%$ potassium, and $\mathrm{pH}$ of 6.69 in the flower pot. The soil burial test procedure in this research was conducted with reference to the previous researches $[19,34$, 35]. The samples were positioned at $6 \mathrm{~cm}$ depth from the top soil surface and $3 \mathrm{~cm}$ above the inner bottom pot. The test was carried out under outdoor environment avoiding ultraviolet (UV) light for 60 days with the following condition: watering $500 \mathrm{~mL}$ every 48 hours to control humidity. Ten day interval, five specimens of each formula were collected, cleaned, and dried at $60^{\circ} \mathrm{C}$ for 6 hours. Subsequently, the physical appearance, percentage weight loss, chemical structure, and flexural properties were determined.

2.5. Physical Appearance and Percentage Weight Loss Observation. The optical microscope (Olympus CX31, E for L) with 20x magnification was employed to examine the physical appearance (e.g., surface morphology and colour) before and after the soil burial test. 
TABLE 1: Percentage of crystallinity of the neat PBS and PBS/RWP biocomposites.

\begin{tabular}{lcccccc}
\hline & PBS & PBS/RWP5 & PBS/RWP10 & PBS/RWP20 & PBS/RWP30 & PBS/RWP40 \\
\hline Crystallinity (\%) & 44.7 & 39.6 & 38.9 & 39.6 & 36.9 & 34.5 \\
\hline
\end{tabular}

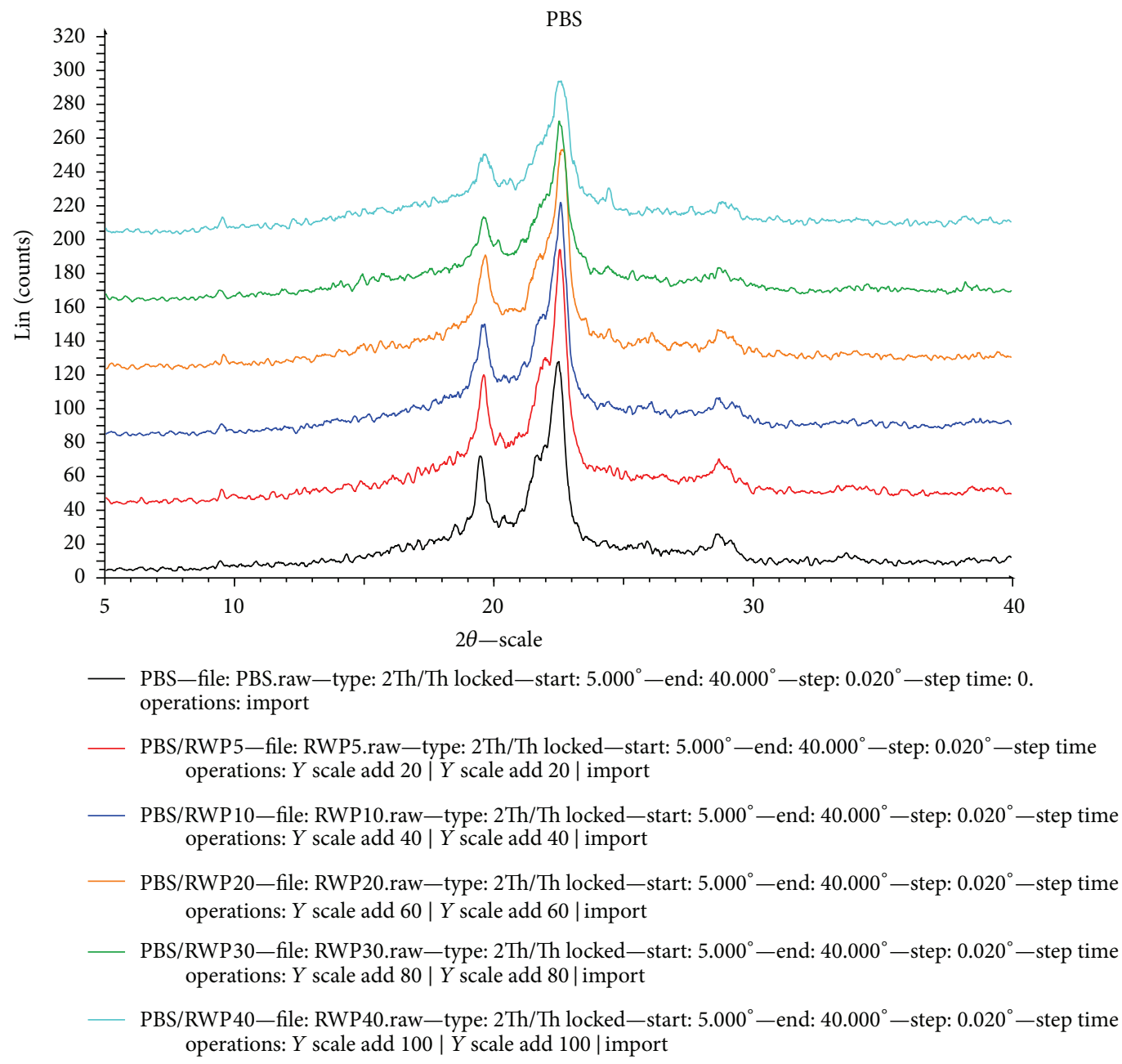

FIGURE 1: X-ray diffractograms of PBS and PBS/RWP biocomposites.

The percentage weight loss of biocomposites was measured using an electronic balance and calculated by using the following:

$$
\text { Weight loss }(\%)=\frac{W_{i}-W_{f}}{W_{i}} \times 100,
$$

where $W_{i}$ and $W_{f}$ are the weight (g) of specimen before and after soil burial test, respectively.

2.6. Flexural Properties. The flexural properties of the neat PBS and PBS/RWP biocomposites were determined in line with ASTM D790. Lloyd L500 Universal Testing Machine (Fareham, UK) was used with $10 \mathrm{kN}$ load cell and $13 \mathrm{~mm} / \mathrm{min}$ crosshead speed. A three-point loading system with a total span length of $50 \mathrm{~mm}$ was performed at the ambient temperature. At least five specimens for each sample were employed.

\section{Results and Discussion}

3.1. X-Ray Diffraction Analysis. X-ray diffraction analyses were conducted to investigate the crystallographic nature of the neat PBS and PBS/RWP biocomposites. The X-ray diffractograms of the neat PBS and PBS/RWP biocomposites, presented in Figure 1, exhibit a typical peak of semicrystalline structure of PBS, that is, two speculate diffraction peaks located at $2 \theta=19.74^{\circ}$ and $2 \theta=22.56^{\circ}$ [36].

It can be observed that the intensity peak of PBS/RWP biocomposites decreases and becomes somewhat broader with increasing the rubberwood powder content. This reveals that an increase of rubberwood powder content results in a decrease of the percentage of crystallinity, as displayed in Table 1. This may be attributed to the presence of rubberwood powders interrupting the arrangement of the molecular chains of PBS matrix (i.e., providing more 
TABLE 2: SEM micrographs of the neat PBS and PBS/RWP biocomposites.

\begin{tabular}{|c|c|c|c|c|c|c|}
\hline Magnification & PBS & PBS/RWP5 & PBS/RWP10 & PBS/RWP20 & PBS/RWP30 & PBS/RWP40 \\
\hline $500 x$ & & & & & & \\
\hline $3000 x$ & & & & & & \\
\hline
\end{tabular}

disordered arrangement). With increase in the rubberwood powder content, a greater loss of its crystallinity is observed, particularly as rubberwood powder content greater than 20 . This may be due to an agglomeration of the rubberwood powders at higher concentration as SEM micrographs result.

The argument of the agglomeration of the rubberwood powders at higher concentration is supported by the SEM micrographs of the neat PBS and PBS/RWP biocomposites at magnifications 500x and 3000x as shown in Table 2. The neat PBS exhibits smooth surface. As increasing the rubberwood powder content, a slightly greater numbers of holes are found, and rough surface is exhibited at high rubberwood powder loading. This is because the PBS matrix may be not enough to encapsulate wood particles and the particle size of wood increases due to the agglomeration of wood particle. It is observable that an average rubberwood particle dimension increases from approximately 50 microns for PBS/RWP5, PBS/RWP10, and PBS/RWP20 biocomposites to around 100 microns for PBS/RWP30 and PBS/RWP40 biocomposites.

\subsection{Physical Appearance and Percentage Weight Loss Analysis} after Soil Burial Testing. Optical micrographs of the neat PBS and PBS/RWP biocomposites surface before and after soil burial test for 60 days at 20x magnification are illustrated in Table 3. Prior to the soil burial test, the neat PBS shows a relatively smooth surface whereas the PBS/RWP biocomposites surface appears to show more impurities with increase in the rubberwood powder content. This may be ascribed to an inadequate compatibility between the hydrophilic RWP and the hydrophobic PBS [37, 38].

Following 60-day soil burial test, an insignificant change in physical appearance was observed for the neat PBS, PBS/RWP5, PBS/RWP10, and PBS/RWP20 biocomposites. Meanwhile, for PBS/RWP30 and PBS/RWP40 biocomposites revealed more obvious changes, such as rougher surface and more cavities and cracks spreading on the sample surface. The presence of cavities on the fractured surfaces of PBS/RWP biocomposites resulted from an elimination of some rubberwood powder phase. This indicates that the biodegradability of these biocomposites primarily originated from the rubberwood powder phase, which is a hydrophilic nature and a hydrobiodegradable characteristic of PBS via hydrolysis mechanism [22, 39].

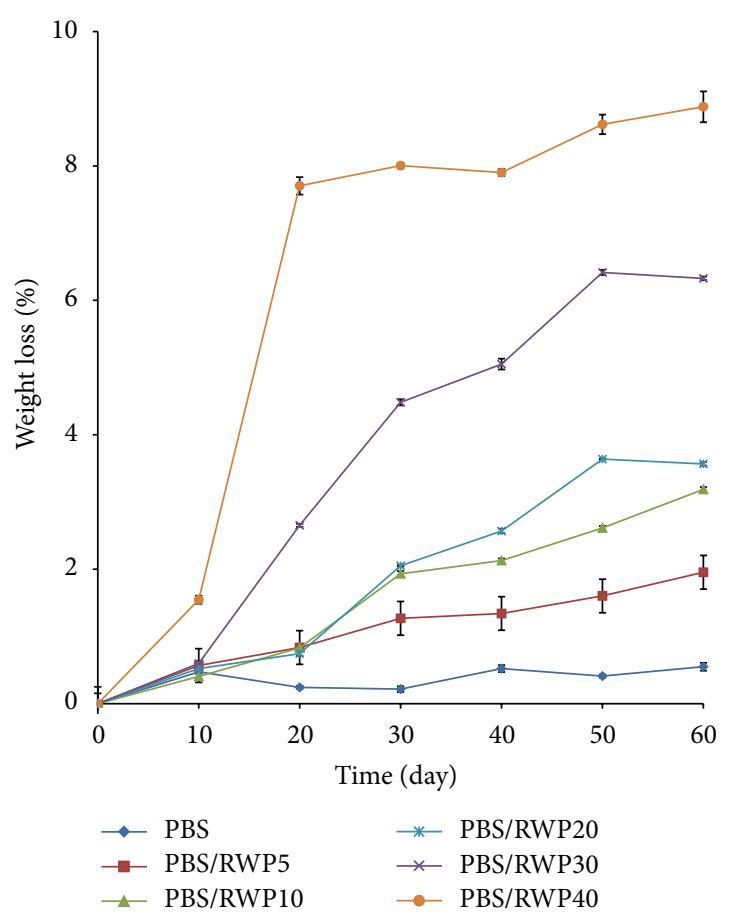

FIgure 2: Percentage weight loss of the neat PBS and PBS/RWP biocomposites.

Additionally, to observe the change of the neat PBS and PBS/RWP biocomposites after soil burial test for 60 days, the percentage weight loss of all samples was measured and shown in Figure 2.

An apparent increase in percent weight loss was noticed for the PBS/RWP30 and PBS/RWP40 biocomposites after soil burial test from 20 days onward. These results are associated with the crystallinity values obtained by X-ray diffraction analysis, that is, greater weight loss as fewer the crystallinity value. This denotes that the percentage of crystallinity appears to be one of the crucial parameters influencing the biodegradation processes since the molecules in the amorphous region are loosely packed, thus making it more vulnerable to degradation $[40,41]$. Moreover, the rate of hydrolysis is also affected by crystallinity due to the easy diffusion of water molecules into amorphous region [42]. This essentially corresponds 
TABLE 3: Optical micrographs of the neat PBS and PBS/RWP biocomposites.

\begin{tabular}{|c|c|c|c|c|c|c|}
\hline Burial time & PBS & PBS/RWP5 & PBS/RWP10 & PBS/RWP20 & PBS/RWP30 & PBS/RWP40 \\
\hline 0 days & & & & & & \\
\hline 10 days & & & & & & \\
\hline 20 days & & & & & & \\
\hline 30 days & & & & & & \\
\hline 40 days & & & & & & \\
\hline 50 days & & & & & & \\
\hline 60 days & & & & & & \\
\hline
\end{tabular}

to the previous research discoveries, which are the plastic chemical and physical properties having important roles in the biodegradation, for example, the surface conditions (surface area, hydrophilic and hydrophobic properties), the firstorder structures (chemical structure, molecular weight, and molecular weight distribution), and the high order structures (glass transition temperature, melting temperature, modulus of elasticity, crystallinity, and crystal structure) of polymers processes [40].

Furthermore, it can be observed that the surface color of PBS/RWP biocomposites faded after biodegradability test. This is owing to an elimination of hydrophilic extractive components, which are low molecular weight organic compounds contributing to colour and odor of woods [43].

3.3. Fourier Transform Infrared (FTIR) Analysis after Soil Burial Testing. The FTIR technique can be used to investigate a performance of hydrolysis of ester linkage in PBS phase via the carbonyl index value. Figure 3 shows the FTIR-ATR spectra of the neat PBS at different soil burial time, presenting distinct peaks at around $1711 \mathrm{~cm}^{-1}$ indicating $\mathrm{C}=\mathrm{O}$ stretching of ester linkage, $1220-1265 \mathrm{~cm}^{-1}$ indicating C-C-O stretching for the functional groups in the ester linkage of PBS, 1045$1149 \mathrm{~cm}^{-1}$ indicating O-C-C stretching vibration for the PBS, and $917 \mathrm{~cm}^{-1}$ for -C-OH bending in carboxylic acid groups $[44,45]$. Following the soil burial test, a considerably reduced absorption intensity of $\mathrm{C}-\mathrm{C}-\mathrm{O}, \mathrm{O}-\mathrm{C}-\mathrm{C}$, and $\mathrm{C}=\mathrm{O}$ stretching was observed.

The carbonyl index values of the neat PBS are shown in Table 4. It can be seen that the carbonyl index values decreased as the burial time increased. These results confirm that the chemical structures of PBS were changed after the compost burial test, mainly due to hydrolysis of the ester bonds, C-C-O and O-C-C, in the main chain [45]. 
TABLE 4: The carbonyl index values of the neat PBS and the PBS/RWP biocomposites.

\begin{tabular}{lccccccc}
\hline & \multicolumn{7}{c}{ Carbonyl index (CI) at various burial times } \\
& 0 days & 10 days & 20 days & 30 days & 40 days & 50 days & 60 days \\
\hline PBS & 3.70 & 3.47 & 3.21 & 3.18 & 3.16 & 2.95 & 3.04 \\
PBS/RWP5 & 3.82 & 3.47 & 3.39 & 3.29 & 3.17 & 2.48 \\
PBS/RWP10 & 3.97 & 3.29 & 2.89 & 2.72 & 2.75 & 2.48 \\
PBS/RWP20 & 3.31 & 3.03 & 2.80 & 2.61 & 2.68 & 2.57 \\
PBS/RWP30 & 3.41 & 2.87 & 2.65 & 2.55 & 2.56 & 2.35 \\
PBS/RWP40 & 3.07 & 2.71 & 2.34 & 2.34 & 2.22 & 2.27 \\
\hline
\end{tabular}

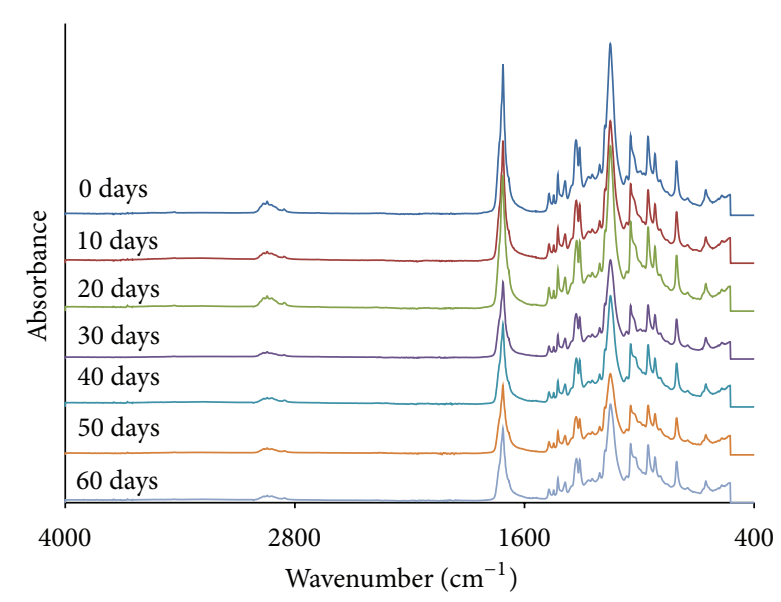

FIGURE 3: FTIR-ATR spectra of the neat PBS at different soil burial time.

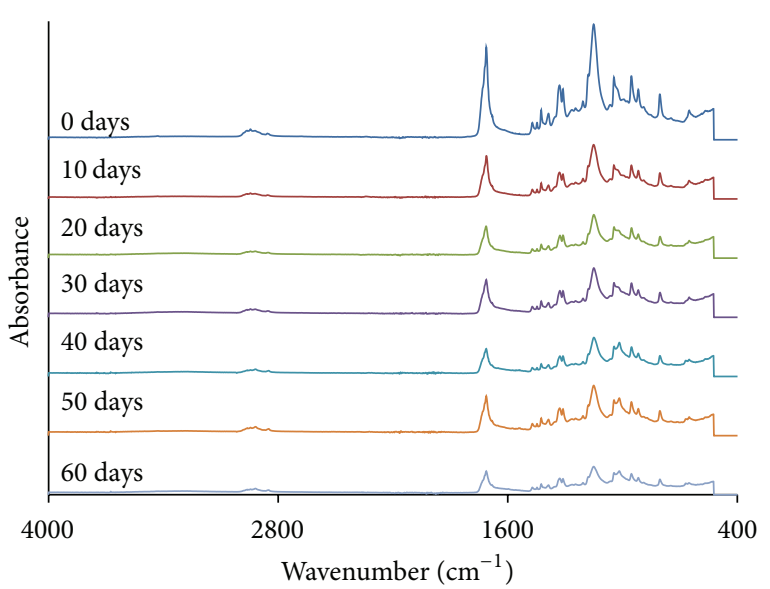

FIGURE 4: FTIR-ATR spectra of the PBS/RWP40 biocomposites at different soil burial time.

Besides, it can be noticed that the carbonyl index values decreased due to enhancing rubberwood powder contents. This once more indicates a change in chemical structures as incorporating rubberwood powders. A similar behavior, that is, decreased as the burial time increased, was observed for the PBS/RWP biocomposites compared with the neat PBS. An example of FTIR-ATR spectra for the PBS/RWP biocomposites is shown in Figure 4.

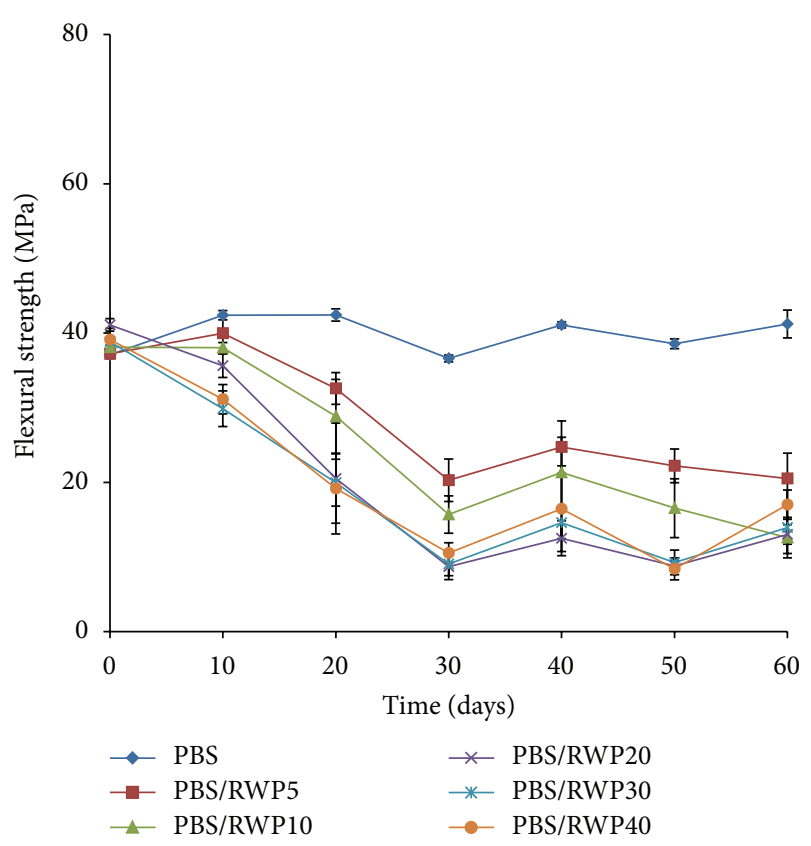

FIgURE 5: Flexural strength of the neat PBS and PBS/RWP biocomposites as a function of burial time.

The spectra of PBS show peaks at $917 \mathrm{~cm}^{-1}$ for $-\mathrm{C}-\mathrm{OH}$ bending in carboxylic acid groups, $1045 \mathrm{~cm}^{-1}$ for -O-C-C stretching vibration, $1144-1264 \mathrm{~cm}^{-1}$ for O-C-C stretching in ester linkages, $1330 \mathrm{~cm}^{-1}$ for symmetric deformational vibrations of $-\mathrm{CH}_{2}$ - groups, $1710-1713 \mathrm{~cm}^{-1}$ for $\mathrm{C}=\mathrm{O}$ stretching vibration of ester groups, and $2945 \mathrm{~cm}^{-1}$ for asymmetric deformational vibration of $-\mathrm{CH}_{2}$ - groups [46]. Following the soil burial test, a considerably reduced absorption intensity of $-\mathrm{CH}_{2}$ - groups (at $1324 \mathrm{~cm}^{-1}$ ) and O-C-C (at $1045 \mathrm{~cm}^{-1}$ ) was observed. This results from amorphous and crystalline cellulose degradation by bacteria and fungi in soil [45].

3.4. Mechanical Properties after Soil Burial Testing. The flexural properties (flexural strength, flexural modulus, and elongation at maximum load) of the neat PBS and PBS/RWP biocomposites before and after soil burial test for 60 days are shown in Figures 5-7.

As seen from Figures 5-7, the flexural properties of the neat PBS barely changed with increase in the burial time, despite the fact that the carbonyl index reduced (i.e., 


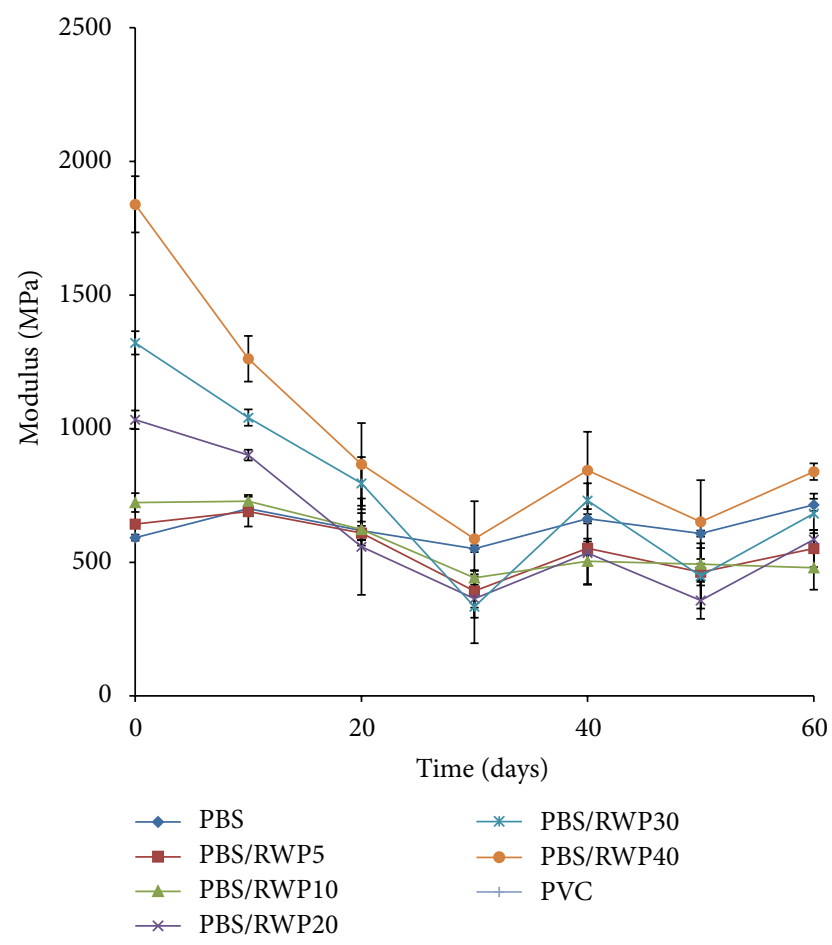

FIGURE 6: Flexural modulus of the neat PBS and PBS/RWP biocomposites as a function of burial time.

indicating an occurrence of the hydrolysis of ester linkage in PBS phase). However, a significant drop in flexural strength and flexural modulus was observed for all of the PBS/RWP biocomposites as the soil burial time increased. These may be attributed to a presence of cavities on the fractured surfaces of PBS/RWP biocomposites as a result of the elimination of some rubberwood powder phase and hydrolysis mechanism of PBS phase, which were more apparent as the soil burial time increased from 20 days onward. This can also be supporting the results from the weight loss analysis (as shown in Figure 2). These results indicate two stages of PBS biodegradable mechanism, which are initially random cleavage of ester linkage leading to a decrease in molecular weight (probably a combination of rubberwood powder elimination and hydrolysis of ester linkage in PBS phase) that affects mechanical properties and then microorganism degradation.

\section{Conclusions}

Biodegradability of the PBS can be enhanced by the incorporation of rubberwood powder as supported by the SEM and optical micrographs illustrating greater cavities on the fractured surfaces of PBS/RWP and higher weight loss, a decline in crystallinity as seen in the X-ray diffractograms, and a more pronounced drop in carbonyl index values. This reveals the presence of rubberwood powders providing more disordered molecular chain arrangement of PBS matrix. This can also be confirmed by deteriorating of flexural properties with increase in soil burial test for 60 days in comparison

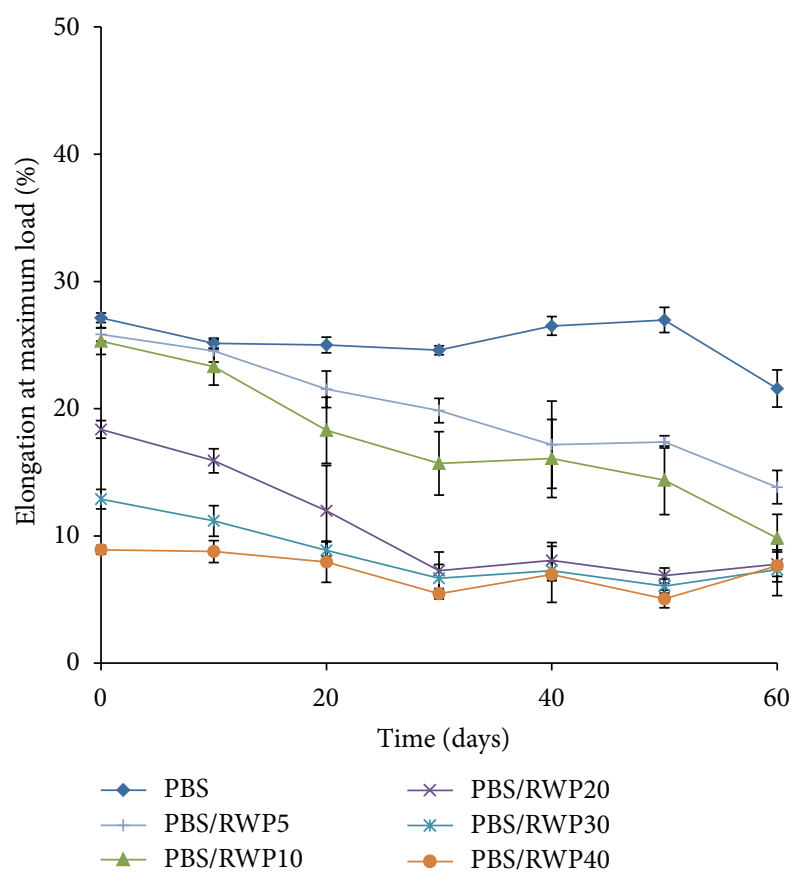

FIGURE 7: Elongation at maximum load of the neat PBS and PBS/RWP biocomposites as a function of burial time.

with the neat PBS. Consequently, it can be concluded that the presence of rubberwood powder promotes the biodegradation rate of $\mathrm{PBS}$ matrix.

\section{Conflict of Interests}

The authors declare that there is no conflict of interests regarding the publication of this paper.

\section{Acknowledgments}

The authors acknowledge the financial support from the 90th Anniversary of Chulalongkorn University Fund (Ratchadapiseksomphot Endowment Fund). The authors are thankful to Department of Materials Science, Faculty of Science, Chulalongkorn University, and PTT Research and Technology Institute for all supports.

\section{References}

[1] D. Y. Kim and Y. H. Rhee, "Biodegradation of microbial and synthetic polyesters by fungi," Applied Microbiology and Biotechnology, vol. 61, no. 4, pp. 300-308, 2003.

[2] H.-S. Kim, H.-S. Yang, H.-J. Kim, and H.-J. Park, “Thermogravimetric analysis of rice husk flour filled thermoplastic polymer composites," Journal of Thermal Analysis and Calorimetry, vol. 76, no. 2, pp. 395-404, 2004.

[3] R. C. Thompson, C. J. Moore, F. S. vom Saal, and S. H. Swan, "Plastics, the environment and human health: current consensus and future trends," Philosophical Transactions of the Royal Society B: Biological Sciences, vol. 364, no. 1526, pp. 21532166, 2009. 
[4] X. Lu, M. Q. Zhang, M. Z. Rong, G. Shi, and G. C. Yang, "Allplant fiber composites. I: unidirectional sisal fiber reinforced benzylated wood," Polymer Composites, vol. 23, no. 4, pp. 624$633,2002$.

[5] T. Nishino, K. Hirao, M. Kotera, K. Nakamae, and H. Inagaki, "Kenaf reinforced biodegradable composite," Composites Science and Technology, vol. 63, no. 9, pp. 1281-1286, 2003.

[6] D. Plackett, T. L. Andersen, W. B. Pedersen, and L. Nielsen, "Biodegradable composites based on L-polylactide and jute fibres," Composites Science and Technology, vol. 63, no. 9, pp. 1287-1296, 2003.

[7] A. Keller, "Compounding and mechanical properties of biodegradable hemp fibre composites," Composites Science and Technology, vol. 63, no. 9, pp. 1307-1316, 2003.

[8] S. M. Lee, D. Cho, W. H. Park, S. G. Lee, S. O. Han, and L. T. Drzal, "Novel silk/poly(butylene succinate) biocomposites: the effect of short fibre content on their mechanical and thermal properties," Composites Science and Technology, vol. 65, no. 3-4, pp. 647-657, 2005.

[9] H.-S. Kim, H.-S. Yang, H.-J. Kim, B.-J. Lee, and T.-S. Hwang, "Thermal properties of agro-flour-filled biodegradable polymer bio-composites," Journal of Thermal Analysis and Calorimetry, vol. 81, no. 2, pp. 299-306, 2005.

[10] S.-H. Lee and S. Wang, "Biodegradable polymers/bamboo fiber biocomposite with bio-based coupling agent," Composites A: Applied Science and Manufacturing, vol. 37, no. 1, pp. 80-91, 2006.

[11] Y.-F. Shih, W.-C. Lee, R.-J. Jeng, and C.-M. Huang, "Water bamboo husk-reinforced poly(butylene succinate) biodegradable composites," Journal of Applied Polymer Science, vol. 99, no. 1, pp. 188-199, 2006.

[12] M. W. Lee, S. O. Han, and Y. B. Seo, "Red algae fibre/poly(butylene succinate) biocomposites: the effect of fibre content on their mechanical and thermal properties," Composites Science and Technology, vol. 68, no. 6, pp. 1266-1272, 2008.

[13] L. Liu, J. Yu, L. Cheng, and W. Qu, "Mechanical properties of poly(butylene succinate) (PBS) biocomposites reinforced with surface modified jute fibre," Composites Part A: Applied Science and Manufacturing, vol. 40, no. 5, pp. 669-674, 2009.

[14] H.-S. Kim, B.-H. Lee, S. Lee, H.-J. Kim, and J. R. Dorgan, "Enhanced interfacial adhesion, mechanical, and thermal properties of natural flour-filled biodegradable polymer biocomposites," Journal of Thermal Analysis and Calorimetry, vol. 104, no. 1, pp. 331-338, 2011.

[15] G. Dorez, A. Taguet, L. Ferry, and J. M. Lopez-Cuesta, “Thermal and fire behavior of natural fibers/PBS biocomposites," Polymer Degradation and Stability, vol. 98, no. 1, pp. 87-95, 2013.

[16] B. P. Calabia, F. Ninomiya, H. Yagi et al., "Biodegradable poly(butylene succinate) composites reinforced by cotton fiber with silane coupling agent," Polymers, vol. 5, no. 1, pp. 128-141, 2013.

[17] P. A. Fowler, J. M. Hughes, and R. M. Elias, "Biocomposites: technology, environmental credentials and market forces," Journal of the Science of Food and Agriculture, vol. 86, no. 12, pp. 1781-1789, 2006.

[18] T. Ohkita and S. H. Lee, "Crystallization behavior of poly(butylene succinate)/corn starch biodegradable composite," Journal of Applied Polymer Science, vol. 97, no. 3, pp. 1107-1114, 2005.

[19] H.-S. Kim, H.-S. Yang, and H.-J. Kim, "Biodegradability and mechanical properties of agro-flour-filled polybutylene succinate biocomposites," Journal of Applied Polymer Science, vol. 97, no. 4, pp. 1513-1521, 2005.
[20] T. H. Nam, S. Ogihara, N. H. Tung, and S. Kobayashi, "Mechanical and thermal properties of short coir fibre reinforced poly(butylene succinate) biodegradable composites," International Journal of Mechanical and Materials Engineering, vol. 5, no. 6, pp. 251-262, 2011.

[21] Y. F. Shih, T. Y. Wang, R. J. Jeng, J. Y. Wu, and C. C. Teng, "Biodegradable nanocomposites based on poly(butylene succinate)/organoclay," Journal of Polymers and the Environment, vol. 15, no. 2, pp. 151-158, 2007.

[22] A. A. Shah, F. Hasan, A. Hameed, and S. Ahmed, "Biological degradation of plastics: a comprehensive review," Biotechnology Advances, vol. 26, no. 3, pp. 246-265, 2008.

[23] R. J. Mueller, Biodegradability of Polymers: Regulations and Methods for Testing, Wiley, Weinheim, Germany, 2003.

[24] E. Rudnik, Compostable Polymer Materials, Elsevier, London, UK, 2008.

[25] C.-S. Wu, "Physical properties and biodegradability of maleated-polycaprolactone/starch composite," Polymer Degradation and Stability, vol. 80, no. 1, pp. 127-134, 2003.

[26] G. Bogoeva-Gaceva, M. Avella, M. Malinconico et al., "Natural fiber eco-composites," Polymer Composites, vol. 28, no. 1, pp. 98$107,2007$.

[27] E. Frollini, N. Bartolucci, L. Sisti, and A. Celli, "Poly(butylene succinate) reinforced with different lignocellulosic fibers," Industrial Crops and Products, vol. 45, pp. 160-169, 2013.

[28] H.-S. Yang, M. P. Wolcott, H.-S. Kim, S. Kim, and H.-J. Kim, "Properties of lignocellulosic material filled polypropylene bio-composites made with different manufacturing processes," Polymer Testing, vol. 25, no. 5, pp. 668-676, 2006.

[29] N. Sombatsompop, C. Yotinwattanakumtorn, and C. Thongpin, "Influence of type and concentration of maleic anhydride grafted polypropylene and impact modifiers on mechanical properties of PP/wood sawdust composites," Journal of Applied Polymer Science, vol. 97, no. 2, pp. 475-484, 2005.

[30] C. G. Guo, Y. M. Song, Q. W. Wang, and C. S. Shen, "Dynamic-mechanical analysis and SEM morphology of wood flour/polypropylene composites," Journal of Forestry Research, vol. 17, no. 4, pp. 315-318, 2006.

[31] S. Rimdusit, W. Smittakorn, S. Jittarom, and S. Tiptipakorn, "Highly filled polypropylene rubber wood flour composites," Engineering Journal, vol. 15, no. 2, pp. 17-30, 2011.

[32] Y. R. Tang, J. Xu, and B. H. Guo, "Tuning the properties of biodegradable poly(butylene succinate) via random copolymerization," Journal of Chemical and Process Engineering, vol. 1, no. 205, pp. 1-5, 2014.

[33] A. Díaz, R. Katsarava, and J. Puiggalí, "Synthesis, properties and applications of biodegradable polymers derived from diols and dicarboxylic acids: from polyesters to poly(ester amide)s," International Journal of Molecular Sciences, vol. 15, no. 5, pp. 7064-7123, 2014.

[34] Y. Phua, N. Lau, K. Sudesh, W. Chow, and Z. A. Ishak, "Biodegradability studies of poly(butylene succinate)/organomontmorillonite nanocomposites under controlled compost soil conditions: effects of clay loading and compatibiliser," Polymer Degradation and Stability, vol. 97, no. 8, pp. 1345-1354, 2012.

[35] R. Kumar, M. K. Yakubu, and R. D. Anandijiwala, "Biodegradation of flax fiber reinforced poly lactic acid," Express Polymer Letters, vol. 4, no. 7, pp. 423-430, 2011.

[36] S.-I. Lee, Y.-S. Lee, K. S. Nahm, Y. B. Hahn, and S.-B. Ko, "Degradable polyurethanes synthesized from poly(butylene 
succinate) polyol, poly(ethylene glycol), and $4,4^{\prime}$-methylenebis(cyclohexyl isocyanate)," Bulletin of the Korean Chemical Society, vol. 21, no. 11, pp. 1145-1148, 2000.

[37] Y. Y. Then, N. A. Ibrahim, N. Zainuddin, H. Ariffin, and W. M. Z. W. Yunus, "Oil palm mesocarp fiber as new lignocellulosic material for fabrication of polymer/fiber biocomposites," International Journal of Polymer Science, vol. 2013, Article ID 797452, 7 pages, 2013.

[38] T. H. Nam, S. Ogihara, N. H. Tung, and S. Kobayashi, "Mechanical and thermal properties of short coir fibre reinforced poly(butylene succinate) biodegradable composites," Journal of Solid Mechanics and Materials Engineering, vol. 5, no. 6, pp. 251262, 2011.

[39] E. Abraham, P. A. Elbi, B. Deepa et al., "X-ray diffraction and biodegradation analysis of green composites of natural rubber/nanocellulose," Polymer Degradation and Stability, vol. 97, no. 11, pp. 2378-2387, 2012.

[40] Y. Tokiwa, B. P. Calabia, C. U. Ugwu, and S. Aiba, "Biodegradability of plastics," International Journal of Molecular Sciences, vol. 10, no. 9, pp. 3722-3742, 2009.

[41] H. Tsuji and S. Miyauchi, "Poly(l-lactide) 6. Effects of crystallinity on enzymatic hydrolysis of poly(l-lactide) without free amorphous region," Polymer Degradation and Stability, vol. 71, no. 3, pp. 415-424, 2001.

[42] K. Cho, J. Lee, and K. Kwon, "Hydrolytic degradation behavior of poly(butylene succinate)s with different crystalline morphologies," Journal of Applied Polymer Science, vol. 79, no. 6, pp. 1025-1033, 2001.

[43] A. L. Horvath, "Solubility of structurally complicated materials: I. Wood," Journal of Physical and Chemical Reference Data, vol. 35, no. 1, pp. 77-92, 2006.

[44] P. Zhao, W. Liu, Q. Wu, and J. Ren, "Preparation, mechanical, and thermal properties of biodegradable polyesters/poly(lactic acid) blends," Journal of Nanomaterials, vol. 2010, Article ID 287082, 8 pages, 2010.

[45] H.-S. Kim, H.-J. Kim, J.-W. Lee, and I.-G. Choi, "Biodegradability of bio-flour filled biodegradable poly(butylene succinate) bio-composites in natural and compost soil," Polymer Degradation and Stability, vol. 91, no. 5, pp. 1117-1127, 2006.

[46] Y. J. Phua, W. S. Chow, and Z. A. M. Ishak, "Reactive processing of maleic anhydride-grafted poly(butylene succinate) and the compatibilizing effect on poly(butylene succinate) nanocomposites," eXPRESS Polymer Letters, vol. 7, no. 4, pp. 340-354, 2013. 

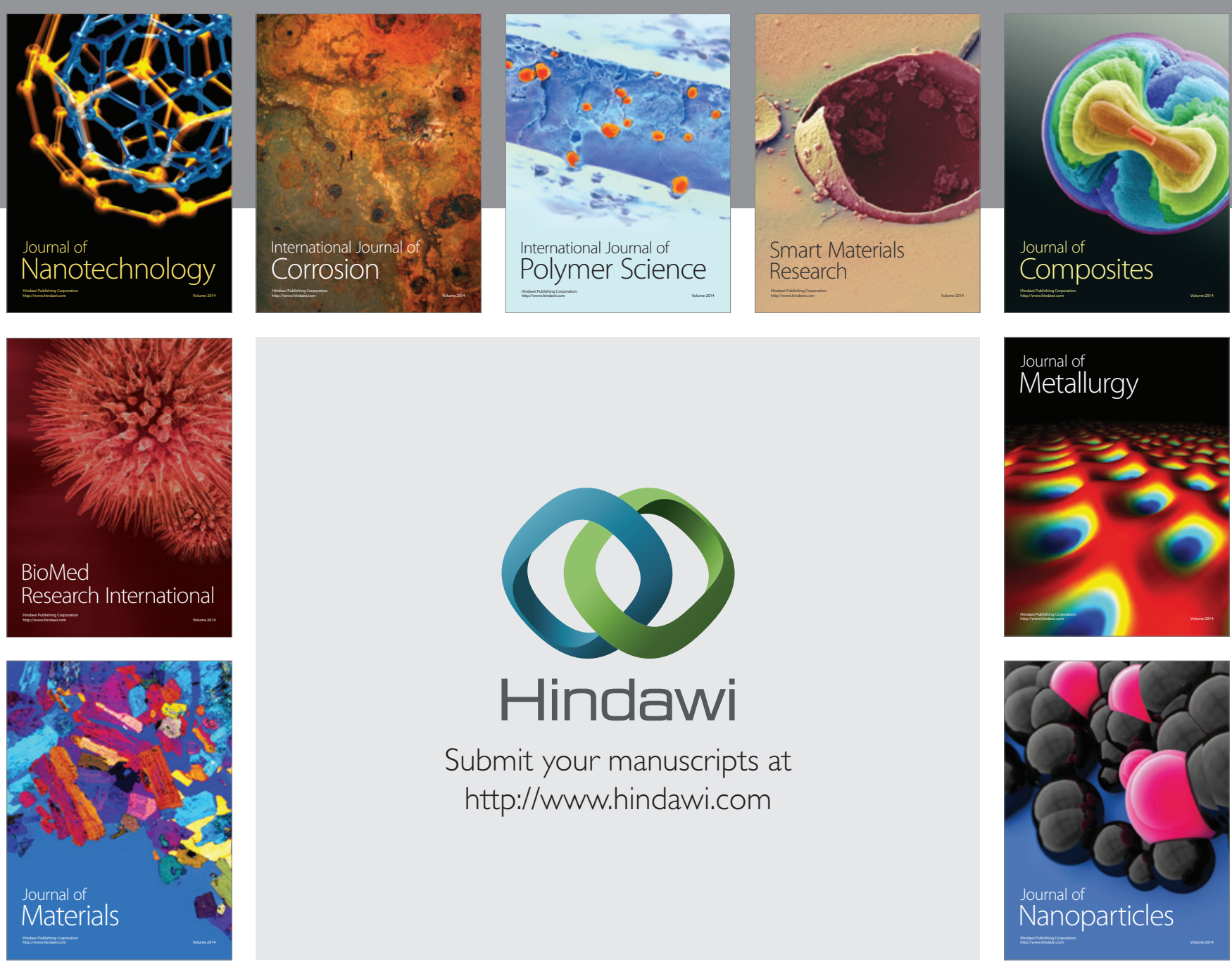

Submit your manuscripts at http://www.hindawi.com
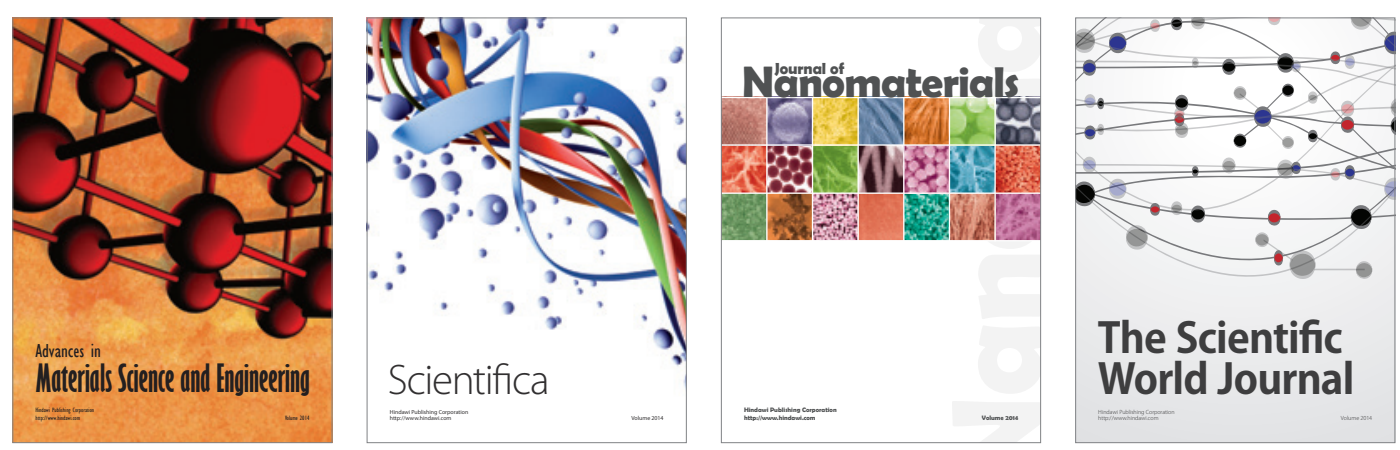

\section{The Scientific World Journal}
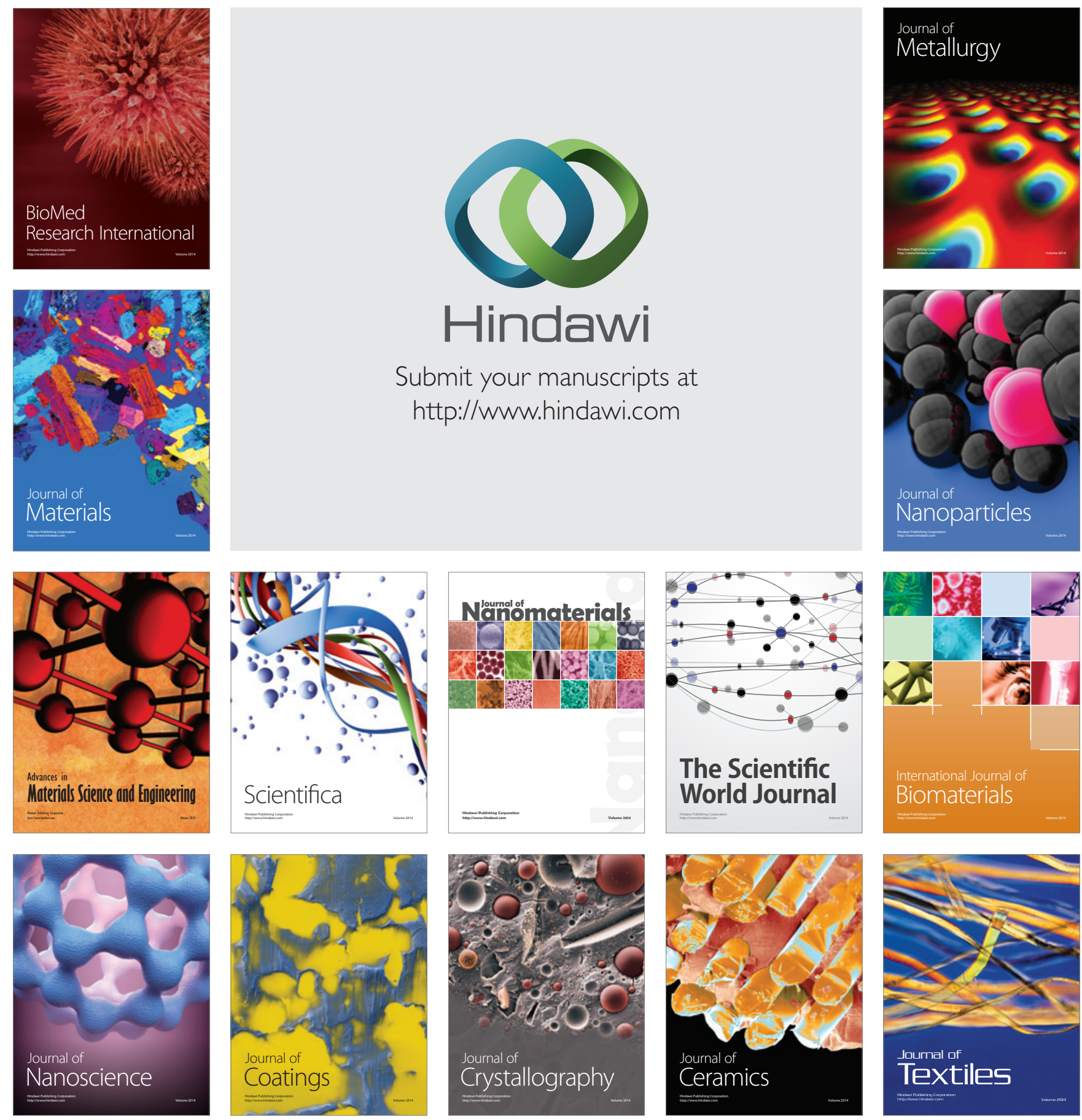